\title{
Studies on Genetic Variability and Character Association among Yield and Yield Attributing Traits in Oats (Avena sativa L.)
}

\author{
R. Premkumar ${ }^{*}$, A. Nirmalakumari ${ }^{2}$ and C.R. Anandakumar ${ }^{3}$ \\ ${ }^{1}$ RVS Agricultural College, Thanjavur, Tamil Nadu - 613 402, India \\ ${ }^{2}$ Plant Breeding and Genetics, Centre of Excellence in Millets, Athiyandal, Thiruvannamalai, \\ Tamil Nadu - 606 603, India \\ ${ }^{3}$ Tamil Nadu Agricultural University, Coimbatore, Tamil Nadu - 641 003, India \\ *Corresponding author
}

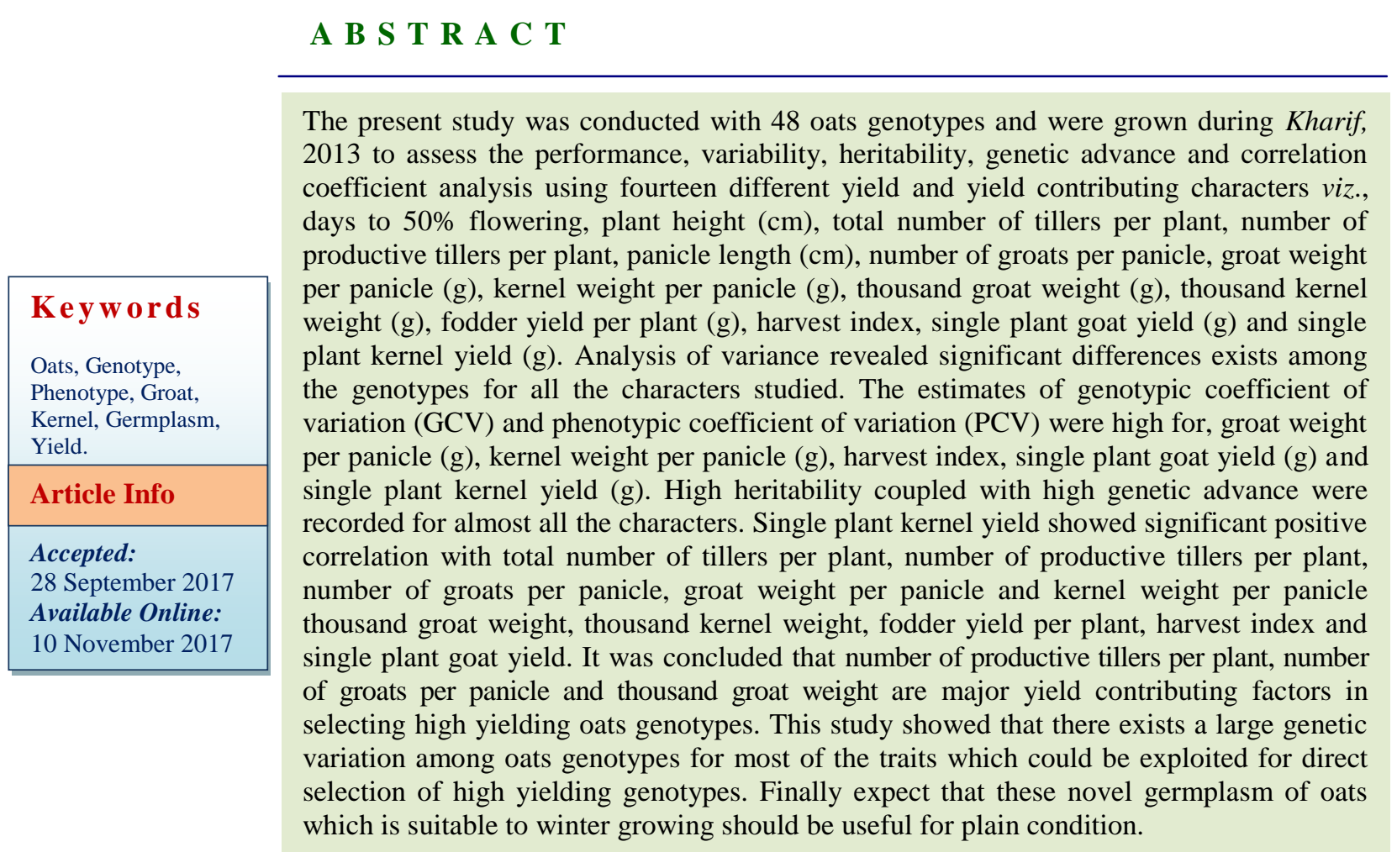

\section{Introduction}

Oats (Avena sativa L.) originated from Mediterranean region, is an important dual (grain and fodder) purpose annual crop of rabi season. It belongs to family poaceae and ranks sixth in production among all cereal crops next to wheat, maize, rice, barley and sorghum in the world scenario. Among the oats genomes, white oats (Avena sativa) and red oats (Avena byzantiana) are cultivated. All over the world, oats was cultivated over 
10.29 million hectares with a production of 20.49 million tonnes. Oat is a constituent of break-fast cereal in most developed countries. The importance of oats in the biochemical and cosmetic industry is also on the rise (Tiwari and Cummins, 2009). Grain yield needs improved to increase the area under oats as an alternative crop especially during winter cultivation. Oats production has continuously decreased, whereas the demand for oats as a human food has increased because of its dietary benefits of the whole grain and $\beta$ glucan content (Buerstmayr et al., 2007). Since oats acreage is much lower than that of most other cereals, commercial efforts in oats breeding is also lower. It can able to tolerate biotic and abiotic stresses to a greater extent and is an alternative choice among the basket of crops for many regions to mitigate the current regime of climate change. Grain yield is the result of a number of complex morphological and physiological processes influencing each other and occurring in different growing stages (Dokuyucu and Akkaya, 1999; Akhtar et al., 2011). In general, oats breeders select varieties based on grain yield and other desirable yield attributing traits, observed from heading to maturity. Agronomic traits have been the primary objective of oats breeders. Besides grain yield, yield components and quality traits, morphological, biological and phenological traits are also important for breeding programs. Considerable importance has been given to studies involving correlation of traits in breeding programs. The quantification and interpretation of these correlations may result in wrong decision making on selection strategies, since a high correlation can be the result of a third trait or a group of traits affecting these traits. This technique identifies and quantifies the existing correlation between two trait complexes. Plant breeders have measured and selected for agronomic traits (grain yield, plant height, heading date, pest and disease resistance as well as lodging), grain physical traits (groat and kernel weight, test weight, groat percentage and milling yield) and grain composition traits (protein, oil, ß-glucan and phyto chemicals) for many years (Peterson et al., 2005). All these traits are affected by genetic and environmental factors (Doehlert et al., 2001). Breeders also develop oats populations for variety development from crosses within regionally adapted germplasms (Achleitner et al., 2008). Unfortunately, as compared with the other cereals such as wheat, maize, rice and barley, less attention has been given to oats. The first step in a breeding programme is to determine the amount of variation that is present in the characters of agronomic importance. Assessment of the genetic variability can be achieved using morphological measurements and phenotypic characterization. Pundhir et $a l$., (2008) studied the genotypic and phenotypic coefficients of variation, heritability, expected genetic advance and correlation and path-analyses in 36 genotypes of oats (Avena sativa L.) over four environments which revealed moderate to high estimates of heritability coupled with high genetic advance for most of the traits. Bahadur et al., (2009) studied oats genotypes to determine the extent of variability for various fodder yield and quality traits under normal and late sown conditions where they found considerable variability existed for all the characters. Present study was undertaken to estimate the variability parameters and correlation coefficients between grain yield and its components characters in oats germplasms.

\section{Materials and Methods}

The present study was carried out during Rabi, 2013 at Indian Agricultural Research Institute, Regional Station, Wellington. A total of 48 genotypes received from IARI, Regional Station, Wellington and Department 
of forages, Centre for Plant Breeding and Genetics, TNAU, Coimbatore and Indian Grassland and Fodder Research Institute, Jhansi were evaluated under field condition using randomized complete block design with three replications. The observations were recorded for yield and its component characters viz., days to $50 \%$ flowering, plant height, total number of tillers per plant, number of productive tillers per plant, panicle length, number of groats per panicle, groat weight per panicle, kernel weight per panicle, thousand groat weight, thousand kernel weight, fodder yield per plant, harvest index, single plant goat yield and single plant kernel yield were studied. The descriptive statistics were worked out. The estimates of variability parameters were worked out according to the method suggested by Lush (1940). Phenotypic and genotypic coefficients of variation were calculated based on the method advocated by Burton (1952). Heritability in broad sense was estimated (Allard, 1960) and expressed in percentage. Genetic advance as per cent of mean was estimated by the method suggested by Johnson et al., (1955). Genotypic correlation coefficients between grain yield and its component traits were used for this analysis. By keeping yield as a dependent variable and the other traits as independent variables, simultaneous equations, which expressed the basic relationship between path coefficients, were solved to estimate the direct and indirect effects.

\section{Results and Discussion}

Analysis of variance revealed significant differences exists among the genotypes for all the characters studied. The mean, range and estimates of phenotypic coefficient of variation (PCV), genotypic coefficient of variation (GCV), heritability in broad sense $\left(\mathrm{h}^{2}(\mathrm{BS})\right)$ and genetic advance as per cent of mean (GA) are presented in Table 1. Days to $50 \%$ flowering showed a range of 57.67 to
98.67 with a mean of 67.82 . The accession, TNAs 20 was found to be very early. Estimates of phenotypic and genotypic coefficients of variation for this character were 15.68 and 15.63 per cent respectively. Plant height exhibited a range of 61.47 to $118.63 \mathrm{~cm}$ with a mean of $94.03 \mathrm{~cm}$. Among all the accessions studied, TNAs 13 had the shortest stature. Muhammad et al., (2002) and Bibi et al., (2012) reported significant difference for plant height in oats genotypes which agreed with the present findings. This character recorded phenotypic and genotypic coefficients of variation of 15.64 and 15.20 per cent respectively. Total number of tillers per plant varied from 3.67 to 12.67 with a mean of 6.56 among the accessions.

The accession, TNAs 41 had the lowest and TNAs 48 had the highest total number of tillers per plant. Estimates of phenotypic and genotypic coefficients of variation for this character were 27.27 and 24.40 per cent respectively. Number of productive tillers per plant showed a range of 3.00 to 9.33 with a mean of 5.07 among the accessions. The accession, TNAs 41 had the lowest and TNAs 48 had the highest total number of tillers per plant. This character recorded phenotypic and genotypic coefficients of variation of 27.95 and 23.46 per cent respectively. Panicle length varied from 16.27 to $30.63 \mathrm{~cm}$ with a mean of $24.15 \mathrm{~cm}$. The accessions TNAs 18 and TNAs 48 had the shortest and the longest panicles respectively. Estimates of phenotypic and genotypic coefficients of variation were 16.06 and 14.60 per cent respectively for this character. Number of groats per panicle ranged from 32.00 to 74.33 with a mean of 51.47. The accessions, TNAs 42 and TNAs 4 had recorded the lowest and highest number of groats per panicle respectively. Phenotypic and genotypic coefficients of variation for this character were 24.55 and 23.28 per cent respectively. Groat weight per panicle ranged from 0.44 to $1.39 \mathrm{~g}$ with a mean of $0.82 \mathrm{~g}$. The accessions, TNAs 30 and TNAs 19 recorded 
the lowest and highest groat weight per panicle respectively. Phenotypic and genotypic coefficients of variation estimates for this character were 37.89 and 36.81 per cent respectively. Kernel weight per panicle ranged from 0.31 to $1.25 \mathrm{~g}$ with a mean of $0.68 \mathrm{~g}$. The accessions, TNAs 30 and TNAs 19 recorded the lowest and highest kernel weight per primary panicle respectively. Phenotypic and genotypic coefficients of variation estimates for this character were 44.05 and 42.62 per cent respectively. Thousand groat weight ranged from 24.51 to 60.90 with a mean of 41.70 per cent. The accessions, TNAs 30 and TNAs 22 recorded the lowest and highest vales for this trait. Estimates of phenotypic and genotypic coefficients of variation were 19.55 and 18.99 per cent respectively. Thousand kernel weight showed a range of $21.86 \mathrm{~g}$ to $58.45 \mathrm{~g}$ with a mean of $39.00 \mathrm{~g}$. The accessions, TNAs 30 and TNAs 22 respectively recorded the lowest and highest thousand kernel weight. Phenotypic and genotypic coefficients of variation estimates were 20.76 and 20.20 respectively. Fodder yield per plant varied from 31.47 to $54.52 \mathrm{~g}$ with a mean of $39.21 \mathrm{~g}$ among the accessions. The accessions, TNAs 1 and TNAs 48 recorded the lowest and highest fodder yield per plant respectively. Estimates of phenotypic and genotypic coefficients of variation were 13.94 and 12.83 per cent respectively. Harvest index ranges between 21.04 to 69.60 with a mean of 37.93 among the accessions. The genotypes, TNAs 2 and TNAs 17 recorded the lowest and highest fodder yield per plant respectively. Single plant groat yield showed a range of 9.55 to $27.12 \mathrm{~g}$ with a mean of $14.94 \mathrm{~g}$. The accessions, TNAs 36 and TNAs 19 recorded the lowest and highest grain yield per plant. Estimates of phenotypic and genotypic coefficients of variation were 38.11 and 36.66 per cent respectively. Single plant kernel yield varied between 7.65 to $24.05 \mathrm{~g}$ with a mean of 12.66g. The accessions, TNAs 7 and TNAs
24 recorded the lowest and highest grain yield per plant. Estimates of phenotypic and genotypic coefficients of variation were 41.01and 39.37 per cent respectively. This high account of variability notified for all the characters showed the possible productivity improvement in oats by direct selection among different genotypes.

\section{Heritability and genetic advance}

The success in any breeding programme depends on the spectrum of genetic variability present in the germplasm. A survey of genetic variability is essentially the first step in crop improvement and plant breeding is an exercise in the management of variability (Hutchinson, 1958). The broad sense heritability gives an idea about the portion of observed variability attributable to genetic difference. Heritability indicates the accuracy with which a genotype can be identified by its phenotypic performance. Burton (1952) suggested that heritability estimates coupled with genotypic coefficient of variation would provide an accurate picture about the extent of genetic advance to be expected through selection. The highest heritability and genetic advance estimates were recorded for the following traits viz., days to $50 \%$ flowering, plant height, total number of tillers per plant, number of productive tillers per plant, panicle length, number of groats per panicle, groat weight per panicle, kernel weight per panicle, thousand groat weight, thousand kernel weight, fodder yield per plant, harvest index, single plant goat yield and single plant kernel yield. None of the traits were recorded lowest heritability and genetic advance (Table 1). The higher estimate of heritability indicated the selection of these traits may be helpful for the improvement of yield. These findings were in agreement with Rahaman and Roquib, 1987; Bahl et al., 1988; Bibi, 2012; Sangwan et al., (2012); Ahmed et al., (2013) and Krishna et al., (2013). 
Table.1 Genetic parameters for different characters in oats genotypes

\begin{tabular}{|c|c|c|c|c|c|c|}
\hline Characters & Mean & Range & GCV (\%) & PCV (\%) & $\mathbf{H}^{2}(\%)$ & GAM (\%) \\
\hline DFF & 67.82 & $57.67-98.67$ & 15.63 & 15.68 & 99.40 & 32.10 \\
\hline $\mathrm{PH}$ & 94.03 & $61.47-118.63$ & 15.20 & 15.64 & 94.30 & 30.40 \\
\hline TNT & 6.56 & $3.67-12.67$ & 24.40 & 27.27 & 80.10 & 44.98 \\
\hline NPT & 5.07 & $3.00-9.33$ & 23.46 & 27.95 & 70.40 & 40.55 \\
\hline PL & 24.15 & $16.27-30.63$ & 14.60 & 16.06 & 82.70 & 27.34 \\
\hline NGP & 51.47 & $32.00-74.33$ & 23.28 & 24.55 & 89.90 & 45.49 \\
\hline GWPP & 0.82 & $0.44-1.39$ & 36.81 & 37.89 & 94.40 & 73.65 \\
\hline KWPP & 0.68 & $0.31-1.25$ & 42.62 & 44.05 & 93.60 & 84.96 \\
\hline TGW & 41.70 & $24.51-60.90$ & 18.99 & 19.55 & 94.20 & 37.99 \\
\hline TKW & 39.00 & $21.86-58.45$ & 20.20 & 20.76 & 94.70 & 40.50 \\
\hline FYP & 39.21 & $31.47-54.52$ & 12.83 & 13.94 & 84.70 & 24.33 \\
\hline $\mathrm{HI}$ & 37.93 & $21.04-69.60$ & 30.03 & 32.28 & 86.60 & 57.56 \\
\hline SPGY & 14.94 & $9.55-27.12$ & 36.66 & 38.11 & 92.50 & 72.64 \\
\hline SPKY & 12.66 & $7.65-24.05$ & 39.37 & 41.01 & 92.10 & 77.84 \\
\hline
\end{tabular}

DFF- days to 50\% flowering, PH- plant height, TNT- total number of tillers per plant, NPT- number of productive tillers per plant, PL- panicle length, NGPnumber of groats per panicle, GWPP- groat weight per panicle, KWPP- kernel weight per panicle, TGW- thousand groat weight, TKW- thousand kernel weight, FYP- fodder yield per plant, HI- harvest index, SPGY- single plant groat yield and SPGY- single plant kernel yield 
Table.2 Genotypic correlation coefficients among yield and yield contributing characters in oat genotypes

\begin{tabular}{|c|c|c|c|c|c|c|c|c|c|c|c|c|c|c|c|}
\hline Characters & DFF & $\mathbf{P H}$ & TNT & NPT & PL & NGP & GWP & KWP & TGW & TKW & DM & FYP & HI & SPGY & SPKY \\
\hline DFF & 1.000 & 0.133 & $0.392^{*}$ & 0.333 & 0.067 & -0.203 & -0.136 & -0.110 & $-0.365^{* * *}$ & $-0.372^{* * *}$ & $0.993^{* *}$ & 0.004 & -0.117 & -0.087 & -0.085 \\
\hline PH & & 1.000 & -0.136 & -0.131 & $0.719^{* * *}$ & -0.052 & -0.178 & -0.149 & $-0.292^{*}$ & $-0.308^{*}$ & 0.143 & 0.096 & -0.072 & -0.026 & -0.023 \\
\hline TNT & & & 1.000 & $0.950^{* * *}$ & -0.014 & $0.409^{* * *}$ & $0.509^{* * *}$ & $0.502^{* *}$ & $0.419^{* * *}$ & $0.418^{* * *}$ & $0.371^{* *}$ & $0.454^{\text {*** }}$ & $0.290^{*}$ & $0.433^{* *}$ & $0.437^{\text {*** }}$ \\
\hline NPT & & & & 1.000 & -0.058 & $0.442^{\text {*** }}$ & $0.632^{* * *}$ & $0.634^{* * *}$ & $0.530^{* * *}$ & $0.522^{* * *}$ & $0.313^{*}$ & $0.431^{\text {** }}$ & $0.463^{* * *}$ & $0.574^{* * *}$ & $0.576^{\text {**k }}$ \\
\hline $\mathbf{P L}$ & & & & & 1.000 & 0.129 & -0.119 & -0.108 & -0.155 & -0.157 & 0.059 & $0.263^{*}$ & -0.177 & -0.073 & -0.068 \\
\hline NGP & & & & & & 1.000 & $0.671^{* * *}$ & $0.653^{* * *}$ & $0.633^{\text {*** }}$ & $0.643^{\text {*** }}$ & -0.205 & $0.559^{\text {*** }}$ & $0.445^{* * *}$ & $0.586^{* *}$ & $0.592^{\text {*** }}$ \\
\hline GWP & & & & & & & 1.000 & $0.997^{* * *}$ & $0.750^{\text {*** }}$ & $0.743^{\text {*** }}$ & -0.144 & $0.505^{\text {**k }}$ & $0.711^{* *}$ & $0.805^{* *}$ & $0.803^{\text {** }}$ \\
\hline KWP & & & & & & & & 1.000 & $0.721^{* *}$ & $0.713^{* * 6}$ & -0.118 & $0.506^{* *}$ & $0.722^{* * *}$ & $0.816^{* * *}$ & $0.814^{\text {** }}$ \\
\hline TGW & & & & & & & & & 1.000 & $0.999^{3 * 6}$ & $-0.386^{\text {** }}$ & $0.454^{* * 6}$ & $0.533^{* * *}$ & $0.614^{* * *}$ & $0.609^{\text {** }}$ \\
\hline TKW & & & & & & & & & & 1.000 & $-0.394^{* * *}$ & $0.452^{\text {** }}$ & $0.517^{* * F}$ & $0.600^{\text {*FF }}$ & $0.596^{\text {** }}$ \\
\hline DM & & & & & & & & & & & 1.000 & -0.013 & -0.102 & -0.079 & -0.078 \\
\hline FYP & & & & & & & & & & & & 1.000 & 0.187 & $0.518^{\text {**a }}$ & $0.525^{\text {** }}$ \\
\hline HI & & & & & & & & & & & & & 1.000 & $0.933^{\text {** }}$ & $0.929^{\text {** }}$ \\
\hline SPGY & & & & & & & & & & & & & & 1.000 & $0.945^{\text {*** }}$ \\
\hline
\end{tabular}

* Significant at $\mathrm{P}=0.05 * *$ Significant at $\mathrm{P}=0.01$

DFF - Days to $50 \%$ flowering

NGP - Number of groats per panicle

PH - Plant height $(\mathrm{cm})$

GWP - Groat weight per panicle (g)

TNT - Total number of tillers per plant

NPT - Number of productive tillers per plant

KWP - Kernel weight per panicle $(\mathrm{g})$

PL - Panicle length (cm)

TGW - Thousand groat weight $(\mathrm{g})$

TKW - Thousand kernel weight (g)

DM - Days to maturity

FYP - Fodder yield per plant $(\mathrm{g})$

HI - Harvest index (\%)

SPGY - Single plant groat yield (g)

SPKY - Single plant kernel yield (g) 
Correlation between kernel yield and its component characters

Correlation coefficients between all pairs of variables used in this experiment are shown in Table 2. At genotypic level single plant kernel yield showed positive and significant correlation with total number of tillers per plant, number of productive tillers per plant, number of groats per panicle, groat weight per panicle and kernel weight per panicle thousand groat weight, thousand kernel weight, fodder yield per plant, harvest index and single plant goat yield These findings were similar to Hussian et al., 1993; Arun et al., 1997 and and Bibi et al., 2012. Days to 50 per cent flowering showed significant negative association with characters namely thousand kernel weight and thousand groat weight. This result was in agreement with the earlier reports of Iannucci et al., (2011) for thousand groat weight. Plant height had significant and positive association with panicle length. Nirmalakumari et al., (2013) and Tang et al., (2014) also observed significant and positive association of this character. Significant and positive correlations of number of productive tillers per plant with kernel weight per panicle, groat weight per panicle, single plant groat yield, thousand groat weight, thousand kernel weight, harvest index, number of groats per panicle, fodder yield per plant and days to maturity were observed. The above result suggested the possibility of selection of one of the above component character would result in the improvement of other characters.

Number of groats per panicle showed significant and positive correlations with groat weight per panicle, kernel weight per panicle, thousand kernel weight, thousand groat weight, single plant groat yield, fodder yield per plant and harvest index. Significant positive association of number of groats per panicle with groat weight per panicle and thousand groat weight was observed earlier by Dumlupinar et al., (2011). Kernel weight per panicle exhibited significant and positive correlation with single plant groat yield, harvest index, thousand groat weight, thousand kernel weight and fodder yield per plant. Thousand groat weight exhibited significant and positive inter correlations with thousand kernel weight, single plant groat yield, harvest index and fodder yield per plant. Thousand kernel weight showed significant and positive correlations with single plant groat yield, harvest index and fodder yield per plant. These results are in conformity with the findings of Krishna et al., (2014) for fodder yield per plant. Harvest index exhibited significant and positive association with single plant kernel yield. This was in agreement with the findings of Iannucci et al., (2011), Hisir et al., (2012) and Nirmalakumari et al., (2013).

Perusal on correlation among component characters revealed that strong associations among desirable component characters are present especially with number of productive tillers per plant, number of groats per panicle and thousand groat weight. Hence, selection criteria should consider all these characters for the improvement of grain yield. Undesirable association of some of the component characters might act as deterrent for the formulation of a comprehensive selection programme involving these traits. So, while formulating a comprehensive selection programme, these factors must be considered with a caution.

\section{Acknowledgement}

The authors here by acknowledge the IARI, Regional Station, Wellington for providing seed material and technical support. Also wish to thank Marico Private Limited for providing funds to carry out this research work. 


\section{References}

Achleitner, A., Tinker, N.A., Zechner, E. and Buerstmayr, H. 2008. Genetic diversity among oat varieties of worldwide origin and associations of AFLP markers with quantitative traits. Theor Appl Genet., 117: 1041-1053.

Ahmed, S., A.K. Roy and A.B. Majumdar. 2013. Correlation and path coefficient analysis for fodder and grain yield related traits in oats (Avena sativa L.). Ann. Biol., 29(1): 75-78.

Akhtar, L.H., Pervez, M.A. and Nasim, M. 2011. Genetic divergence and interrelationship studies in chickpea (Cicer arietinum L.). Pak. J. Agri. Sci., 48: 3539.

Allard, R.W. 1960. Principles of plant breeding. John Wiley and Sons Inc., U.S.A.

Arun, K., Singh, D.N. and Kumar, A. 1997. Correlation and path coefficient analysis in multicut oats, Madras. Agri. J., 84 (9): 541-543.

Bahadur, R. and Choubey, R.N. 2009. Genetic divergence in forage oat (Avena Sativa L.). Forage Res., 34(4): 225-229.

Bahl, A., Rao, S.K. and Singh, C.B. 1988. Association analysis of fodder yield and its components in different environments in oats. Crop Improvement, 15 (2): 132-137.

Bibi, shahzad, A.N., Sadaqat, H.A., Tahir, M.H.N. and Fatima, B. 2012. Genetic characterization and inheritance studies of oats (Avena Sativa L.) For green fodder yield. Int.J.Bio.Pharmacy and Food.Sci., 1 (4): 450-460.

Buerstmayr, H., Krenn, N., Stephan, U., Grausgruber, H. and Zechner, E. 2007. Agronomic performance and quality of oat (Avena sativa L.) genotypes of worldwide origin produced under central European growing conditions. Field Crops Res., 101: 341-351.
Burton, G.W. 1952. Quantitative inheritance in grasses. In: Proc. of the 6th International Grassland Congress, $p p$ 277-283.

Doehlert, D.C, McMullen, M.S. and Hammond, J.J. 2001. Genotypic and environmental effects on grain yield and quality of oat grown in North Dakota. Crop Sci., 41: 1066-1072.

Dokuyucu, T. and Akkaya, A. 1999. Path coefficient analysis and correlation of grain yield and yield components of wheat (Triticum aestivum L.) genotypes. Rachis Newsletters, 18 (2): 17-20.

Dumlupinar, Z., H. Maral, R. Kara, T. Dokuyucu and A. Akkaya. 2011. Evaluation of Turkish oat landraces based on grain yield, yield components and some quality traits. Tur. J Field Crops, 16(2): 190-196.

Hisir, Y., R. Kara and T. Dokuyucu. 2012. Evaluation of oat (Avena sativa L.) genotypes for grain yield and physiological traits. Agriculture, 99(1): 55-60.

Hussain, A., Muhammad, D., Khan, S. and Bhatti, M.B. 1993. Forage yield and quality potential of various cultivars of oats (Avena sativa L.). Pak. J. Sci. Indust. Res., 36 (6-7): 258-260.

Hutchinson, J.B. 1958. Genetics and the improvement of tropical crops. Cambridge University Press.

Iannucci, A., P. Codianni and L. Cattivelli. 2011. Evaluation of Genotype Diversity in Oat Germplasm and Definition of Ideotypes Adapted to the Mediterranean Environment. Int. J. Agron., 2011: 1-8.

Johnson, H.W., Robinson, H.F. and Comstock, R.E. 1955. Estimates of genetic and environmental variability in soybean. Agron. J., 47: 314-318.

Krishna, A., S. Ahmed, H.C. Pandey and D. Bahukhandi. 2013. Estimates of Genetic variability, heritability and genetic advance of oat (Avena sativa L.) 
genotypes for grain and fodder yield. Agric. Sci. Res. J., 3(2): 56-61.

Krishna, A., Shahid Ahmed, H.C. Pandey and K. Vikas. 2014. Correlation, path and diversity analysis of oat (Avena sativa L.) genotypes for grain and fodder yield. J. Plant Sci. Res., 1(1): 110.

Lush, J.L. 1940. Intra - sire correlation and regression of offspring on dams as a method of estimating heritability of characters. In: Proc. of "American Society of Animal Production" 33: 293 301.

Muhammad, N., Khan, M.A., Chohan, M.S.M., Khan, A.H. and Salahuddin, S. 2002. Evaluation of different varieties of oats for green fodder yield potential, Asian J. Pl. Sci., 1 (6): 640-641.

Nirmalakumari, A., R. Sellammal, G. Thamodharan, T. Ezhilarasi and T. Balasubramanian. 2013. Qualitative characterization and assessment of variability in oat genotypes. Green Farming. 6: 749-752.

Peterson, D.M., Wesenberg, D.M., Burrup, D.E. and Erickson, C.A. 2005. Relationships among agronomic traits and grain composition in oat genotypes grown in different environments. Crop Sci., 45: 1249-1255.

Pundhir, S.R., Singh, V.P. and Phogat, D.S. 2008. Genetic variability and interrelationship for various grain and seedling characters in oats, Forage Res., 33: 236-240.

Rahaman, R. and Roquib, M.A. 1987. Genetic variability in fodder oats (Avena sativa), Environment and Ecology, 5 (4): 747750.

Sangwan, O., A. Ram, R.N. Arora and S. Amit. 2012. Variability and character association studies in fodder oat (Avena sativa L.). Forage Res., 38(1): 56-58.

Tang X.Q., H.Y. Hong, Y.W. Zhi, L. Wei, M.W. Yu, Z.R. Chang, Z. Gang and Y.P. Yuan. 2014. Evaluation of diversity and the relationship of Avena species based on agronomic characters. Int. J. Agric. Biol., 16: 14-22.

Tiwari, U. and Cummins, E. 2009. Simulation of the factors affecting $\beta$-glucan levels during the cultivation of oats. J. Cereal Sci., 50: 175-183.

\section{How to cite this article:}

Premkumar, R., A. Nirmalakumari and Anandakumar, C.R. 2017. Studies on Genetic Variability and Character Association among Yield and Yield Attributing Traits in Oats (Avena sativa L.). Int.J.Curr.Microbiol.App.Sci. 6(11): 4075-4083.

doi: https://doi.org/10.20546/ijcmas.2017.611.477 